\title{
A RESPONSE TO GORDON BRISCOE
}

\section{Michael Dodson}

The thing that most disappoints me about Mr Briscoe's article on Kevin Gilbert is its posthumous release. It is impossible for the dead to respond, that task is left to the survivors. Kevin Gilbert was a survivor in every sense - I like to remember him like that.

Mr Briscoe's article is in part factually incorrect, an essential flaw for an historian writing about history I have thought. I leave it for members of Kevin's family to correct these errors but their making immediately raises the alarm about the article and the intentions of $\mathrm{Mr}$ Briscoe.

I think his writings tell us more about Mr Briscoe than about Kevin Gilbert. The struggle for grace is Gordon's not Kevin's. The events of history (and a person's life is an event of history) is not usually clearly organised and non chaotic. The opposite is true. Kevin Gilbert's life may be described by some as chaotic and wandering. But it is predicated with the self expressions of how he saw the events and lives around him. We may not agree with his expressions ( $\mathrm{Mr}$ Briscoe rejects many of them) but they were his. He had things to say - Mr Briscoe tries - unsuccessfully in my view - to examine why he said them. We will never know. The man is dead. We do know he made a contribution, to disregard that contribution is to disregard history. Disregarding history can and does produce fatal consequences.

Spurious and fallacious attacks on the dead man's personal life ignores the historical part Kevin Gilbert made in informing and enriching the lives of many of us.

Michael Dodson is the Aboriginal \& Torres Strait Islander Social Justice Commissioner, at the Human Rights and Equal Opportunity Commission 